\title{
An Analysis of Host Adaptation and Its Relationship with Virulence in Cucumber mosaic virus
}

\author{
Soledad Sacristán, Aurora Fraile, José M. Malpica, and Fernando García-Arenal
}

\begin{abstract}
First, second, and fourth authors: Departamento de Biotecnología, E.T.S.I. Agrónomos, Universidad Politécnica de Madrid, 28040 Madrid, Spain; and third author: Departamento de Biotecnología, Instituto Nacional de Tecnología Agraria y Alimentaria, Ctra. de La Coruña km 7.5, 28040 Madrid, Spain.
\end{abstract}

Accepted for publication 16 March 2005.

\begin{abstract}
Sacristán, S., Fraile, A., Malpica, J. M., and García-Arenal, F. 2005. An analysis of host adaptation and its relationship with virulence in Cucumber mosaic virus. Phytopathology 95:827-833.

The host range of a pathogen can have special consequences on its evolution and the evolution of its virulence. For generalists, adaptation to different hosts may be conditioned by different trade-offs in the pathogen's life history and be affected by evolutionary processes that shape pathogen populations. We have examined adaptation of Cucumber mosaic

experimental evolution process consisting of 10 serial passages in the original host of the isolate. The differential capacity to infect different hosts was compatible with host adaptation. However, the capacity to multiply in different hosts did not provide evidence of host adaptation and was not improved after 10 passages, suggesting that fitness of the natural population of CMV was at, or near to, its maximum. No relationship was found between capacity of multiplication and virulence in any of the three different hosts. These results suggest that the "trade-off" model for the evolution of virulence may not apply to CMV.
\end{abstract} virus (CMV) to different hosts, and analyzed the relationship between host adaptation and virulence. For this, six CMV isolates from central Spain from three different hosts were compared for the ability to multiply and to affect host growth. These analyses were done before and after an
Additional keywords: multihost pathogens, virulence evolution, virus evolution.
Virulence, defined as the effect of a pathogen on host fitness, is a quintessential property of pathogens. Virulence may be selectable and, thus, could play an important role in the evolution of pathogens (39). Understanding the selective factors that determine virulence evolution is key for development of efficient and sustainable control strategies. The host range of the pathogen (i.e., whether the pathogen is a generalist or a specialist) is predicted to be a major factor in the evolution of virulence $(5,12)$. The generalist strategy (the adaptation of a pathogen to many different hosts) could facilitate successful transmission and dispersal dynamics, survival during unfavorable periods, and exploit spatial and temporal configuration of susceptible hosts. However, theoretical predictions $(1,4,12)$ do not favor the generalist strategy. Most models of virulence evolution are based on the concept, which still must be verified in-depth $(6,8)$, that virulence is an unavoidable consequence of the multiplication of the pathogen within the host. Under this assumption, the evolution of pathogens would be subjected to a trade-off between virulence and transmission, so that selection within and between hosts would result in a level of virulence that optimizes both multiplication and transmission of the pathogen $(1,12)$, in what is called the trade-off model. If different hosts represent different selective environments, the virulence level that maximizes fitness of the pathogen in one host may not do so for other hosts (37). Hence, virulence may result from trade-offs in the adaptation to multiple hosts $(5,23,25)$ with different levels of virulence in a pathogen population due to diverse selective pressures imposed by different hosts $(29,40)$. Trade-offs in adaptation to different hosts could

Corresponding author: F. García-Arenal

E-mail address: fernando.garciaarenal@upm.es

DOI: 10.1094/PHYTO-95-0827

(C) 2005 The American Phytopathological Society result in differentiation of a pathogen population according to host and significantly influence pathogen population dynamics and epidemiology.

Although not abundant, there is some evidence in support of the theoretical predictions described above. For example, natural populations of pathogens with broad host ranges often contain different genetic variants associated with different host species $(21,28,31,45)$. Also, the acquisition of virulence on a particular host genotype often results in a reduced fitness on other host genotypes, as has been shown for resistance-breaking strains of several plant viruses $(15,20)$. Serial passage experiments generally show that adaptation of a pathogen to a new host involves a decrease in fitness in the host of origin $(7,9)$. Collectively, these studies support the existence of costs linked to pathogen adaptation to new hosts that could limit fitness of generalist pathogens (23).

We addressed host adaptation and its relationship with virulence using as an experimental system Cucumber mosaic virus (CMV), a well characterized multihost plant pathogen. CMV, type member of the genus Cucumovirus, has isometric particles that encapsidate a tri-partite single-stranded RNA genome of messenger-sense polarity. The genomic segments RNA 1 and RNA 2 encode proteins $1 \mathrm{a}$ and $2 \mathrm{a}$, respectively, which are part of the virus RNA-dependent RNA polymerase. RNA 2 also encodes protein $2 b$, a suppresser of posttranscriptional gene silencing. RNA 3 encodes the 3 a protein (required for cell-to-cell movement within the infected plant) and the coat protein (the structural protein of virions also required for cell-to-cell and long-distance systemic movement, and for aphid transmission). CMV has the broadest known host range of any plant virus, infecting more than 1,200 host species in more than 100 plant families and is transmitted by more than 80 aphid species (reviewed in 34-36). Because CMV is transmitted nonpersistently, hibernating aphids, or long-distance migrants, are not sources of inocula. Hence, alternative hosts 
likely have great epidemiologic importance as reservoirs and inoculum sources for annual hosts (36). Thus, frequent change of host could affect fitness if there are trade-offs for host adaptation. Molecular determinants of the differential capacity of CMV strains to infect some hosts are known, and if pleiotropic to other functions (35), trade-offs could be associated with host adaptation. Trade-offs for host adaptation also could result in differential adaptation of CMV to different hosts, thereby affecting population structure and dynamics.

In this work, we analyzed adaptation of CMV to different hosts by comparing the fitness of six CMV isolates in their original hosts and in other hosts before, and after, a serial passage process of experimental evolution in their host of origin. The results of this experiment provide evidence of host-associated differential infectivity but not of host-associated differential accumulation, and suggest that the fitness of most natural isolates is at, or near, its maximum. Also, the results show no relationship between fitness and virulence in CMV.

\section{MATERIALS AND METHODS}

Viruses and plants. Six CMV isolates, two from each of three different hosts plant species, were randomly chosen from our laboratory's collection: isolates C/99/4 and C/99/5 from cucumber (Cucumis sativus L.), $\mathrm{Ph} / 94 / 12$ and $\mathrm{Ph} / 94 / 13$ from bean (Phaseolus vulgaris L.), and T/93/2 and T/99/4 from tomato (Lycopersicon esculentum Mill.). These isolates were collected during CMV outbreaks in central Spain from 1993 to 1999 (2). Each isolate came from one field-infected plant and was multiplied once in its host of origin. Viral particles were purified (26) and virion RNA was extracted (17). These viral RNA preparations were named P0 and used as starting inocula for passages. Hosts for viral multiplication, and for serial passages and assay of virus accumulation and virulence, were cucumber cv. Toril, bean cv. Contender, and tomato cv. Marglobe. These cultivars have similar genetic backgrounds to those grown in central Spain.

Serial passages. Each CMV isolate was serially passaged 10 times in its original host. The first passage was initiated by inoculating virion RNA from P0 preparations $(100 \mu \mathrm{l}$ of a $100-\mu \mathrm{g} / \mathrm{ml}$ RNA suspension in $0.1 \mathrm{M} \mathrm{Na}_{2} \mathrm{HPO}_{4}$ ) onto seven plants of the host of origin. Each of these plants was the starting point of an independent series of passages, or lines, performed at two different inoculum doses, a high and a low inoculum dose (lines $\mathrm{H}$ and $\mathrm{L}$, respectively). For each passage, sap from infected plants in the previous passage was used as inoculum, which was applied to all the expanded leaves of two- (cucumber and bean) or three(tomato) week old plants. In high inoculum dose passages, tissue samples randomly taken from all systemically infected leaves were ground in inoculation buffer $(10 \mathrm{mM}$ sodium phosphate buffer, $\mathrm{pH} 7$, and $0.2 \%$ dietyltiocarbamate) at a $1: 1$, weight/volume, ratio to be used as inoculum. Five plants per line were inoculated with $100 \mu \mathrm{l}$ of inoculum per plant, and one of these five plants was randomly chosen to start the next passage. In low inoculum dose passages, the sap extract was diluted 1:10 to 1:1,000, depending on the isolate and passage, such that only one or two of five inoculated plants were infected; otherwise, the procedure was the same as for the high inoculum dose passages. Infectivity of the inoculum in each passage was measured by local lesion assay (3) in Chenopodium quinoa Willd. using at least two dilutions of sap extracts. Infection by CMV in systemic hosts was verified by double-antibody sandwich enzyme-linked immunosorbent assay using commercial antisera (Bio-Rad, Marnes-La-Coquette, France) according to the manufacturer's instructions. During the course of the passage experiments at least 10 mock-inoculated plants were randomly distributed among inoculated plants, as controls for cross-contamination. No mock-inoculated plant was infected at the time of harvest for each passage. Plants were kept in a greenhouse at 20 to $30^{\circ} \mathrm{C}$ and $16 \mathrm{~h}$ light. After 10 passages, each line was independently harvested, CMV particles were purified, and virion RNA was extracted. These viral RNA preparations were called P10.

Assay of CMV accumulation and of the effect of CMV infection on host growth. The accumulation of each P0 and P10 preparation for all six CMV isolates, and the effect of their infection on host growth, was assayed in the three hosts species (cucumber, bean, and tomato) such that each P0 and P10 preparation was assayed in the host of origin and in the other two hosts (from here on called heterologous hosts). In each assay, five plants were inoculated with each $\mathrm{P} 0$ and $\mathrm{P} 10$ preparations, using $50 \mu \mathrm{l}$ of virion RNA suspensions $(20 \mu \mathrm{g} / \mathrm{ml})$. Five plants of each host, mock-inoculated with $0.1 \mathrm{M} \mathrm{Na}_{2} \mathrm{HPO}_{4}$, were used as negative controls. Plants were harvested at 21 days postinoculation (dpi). In these assays, deviation of the results of infectivity of the various isolates (fraction of infected plants) from the null hypothesis of no differences were measured by the chi-square test, and its significance was assessed by randomization.

Quantification of viral RNA accumulation was done by dot blot hybridization in nylon membranes of total nucleic acid extracts of leaf tissue (10) randomly sampled from all the systemically infected leaves of each plant. Hybridization was carried out at $65^{\circ} \mathrm{C}$ with a ${ }^{32} \mathrm{P}$-labeled RNA probe transcribed from a cDNA clone containing nucleotides 1933 to 2215 of CMV-Fny RNA 3 (GenBank accession no. NC 001440). The probe sequence corresponded to the $3^{\prime}$ untranslated region, which is identical for all three genomic RNAs of CMV (36). In each blot, internal standards of Fny-CMV were included as a twofold dilution series of purified virus RNA ( 2 to $0.015 \mu \mathrm{g}$ ) in nucleic acid extracts from noninoculated plants of each of the assayed host species. Different amounts of nucleic acid extracts from each sample to be analyzed were blotted to ensure that the hybridization signal was within the range for which hybridization signal corresponded to RNA concentration in a linear fashion. As an RNA-loading control, replicas of the dot blotted membranes were hybridized with a cDNA probe (approximately 800 nucleotides long) complementary to barley $18 \mathrm{~S}$ rRNA (16). After exposure to the radioactively labeled samples, the $\mathrm{Eu}^{+2}$ store phosphor screens were scanned in a Typhoon 9400 scanner (Amersham Biosciences, Piscataway, NJ) and densitometry was done using the program ImageQuant 5.2. (Molecular Dynamics, Amersham Biosciences).

Due to heterogeneity of variances for virus accumulation data, nonparametric tests were employed for statistical analyses. The accumulation of CMV according to the original host of the isolate was analyzed by the Scheirer-Ray-Hare extension of the KruskalWallis test in lieu of two-way analysis of variance (ANOVA) (43). The accumulation of CMV before and after the passages at high and low inoculum dose was compared by the Kruskal-Wallis test in lieu of one-way ANOVA (22).

The effect of CMV on host growth $(V)$ was determined as the relative difference in dry weight of the above-ground parts of each infected plant in relation to the mock-inoculated controls, calculated as $V=1-P i / P s$, where $P i$ is the dry weight of the inoculated plant and $P S$ is the average dry weight of five mock-inoculated plants of the same host. Dry weight was determined by maintaining the harvested plants at $65^{\circ} \mathrm{C}$ until constant weight. The effect of CMV infection according to the original host of the isolate was analyzed by two-way ANOVA. The effects of CMV infection before and after the passages at high and low inoculum dose were compared by one-way ANOVA. All other statistical analyses were as described by Sokal and Rohlf (46).

RNA sequence analyses. The consensus sequence of one randomly chosen fragment of each of the three genomic RNA segments was determined for each $\mathrm{P} 0$ and $\mathrm{P} 10$ preparation. Those three fragments were delimited by nucleotide positions 173 to 909 in RNA 1, 408 to 1001 in RNA 2, and 166 to 581 in RNA 3. These fragments were reverse transcription-polymerase chain reaction (RT-PCR) amplified using primers complementary and identical, 
respectively, to positions 962 to 981 and 137 to 156 of RNA 1, 1109 to 1128 and 298 to 317 of RNA 2, and 978 to 998 and 114 to 131 of RNA 3 (nucleotide sequence of primers and positions numbering as in Fny-CMV RNAs 1, 2, and 3, GenBank accession nos. NC-002034, NC-002035, and NC-001440), and the RT-PCR products were directly sequenced using an ABI Prism A310 Automated Sequencer (Applied Biosystems, Foster City, CA). Sequences are available from the EMBL database under accession nos. AJ888919 to AJ888950 and AJ889021 to AJ889084. Nucleotide sequences were aligned using the program ClustalX 1.83 (47). Genetic distances among sequences were estimated as pdistances (number of nucleotide substitutions/total length of the RNA fragment) (32).

\section{RESULTS}

Infectivity and accumulation of CMV isolates in the original and heterologous hosts. Accumulation of the original six CMV isolates ( $\mathrm{P} 0$ preparations) was assayed in the host of origin and in the two heterologous hosts. Table 1 shows the proportion of infected plants and Table 2 shows the average accumulation, according to the host of origin, in all three hosts. Infectivity of the P0 preparations was significantly different in each assayed host $\left(\chi_{2}^{2}=26.56, P<10^{-3}\right)$; significantly fewer bean plants became infected compared with cucumber and tomato. Furthermore, infectivity in bean depended on the host of origin of the isolate $\left(\chi_{2}{ }^{2}=7.60, P=0.02\right)$, with isolates from bean infecting a higher proportion of plants than those from cucumber or tomato.

CMV accumulation was significantly different among the three hosts $\left(P=2 \times 10^{-9}\right)$, being lower in bean and higher in tomato (Table 2). However, virus accumulation did not differ significantly according to isolate host of origin $(P=0.19)$, nor was a significant interaction between host of origin and assay host found $(P=0.37)$.

Effect of 10 passages in the original host on the infectivity and accumulation of CMV isolates. Each CMV isolate was passaged 10 times in its host of origin at a high inoculum dose. Seven parallel passage lines were established for each isolate, but during the experiment several lines became extinct before passage 10. At the end of the process, viral RNA from at least three lines for each isolate was obtained, yielding virion RNA preparations named $\mathrm{P} 10 \mathrm{H}$. The accumulation of the $\mathrm{P} 10 \mathrm{H}$ preparations for the six CMV isolates in the three hosts was assayed for three lines per isolate, to simplify experimental design. Table 1 shows the proportion of infected plants, and Table 2 shows the average accumulation in all three hosts.

Infectivity of the isolates did not change before and after 10 passages; the frequency of infected plants by $\mathrm{P} 0$ and $\mathrm{P} 10 \mathrm{H}$ preparations was the same (Spearman's coefficient $r_{s}=0.93[P=$ $0.005]$, product-moment correlation coefficient $r=0.96$ ). Infectivity in bean was less than in cucumber or in tomato (Table 1) $\left(\chi^{2}=41.5, P<10^{-3}\right)$. For $\mathrm{P} 10 \mathrm{H}$ preparations, infectivity in bean depended on the host of origin $\left(\chi^{2}=11.9, P=0.004\right)$, isolates from bean being more infective for bean than those from cucumber or tomato. Also, as was the case for the P0 preparations, virus accumulation of $\mathrm{P} 10 \mathrm{H}$ was significantly different in each assayed host $\left(P=3 \times 10^{-24}\right)$, being higher in tomato and lower in bean. Differences in virus accumulation according to the host of origin departed from the null hypothesis (no differences) with $P=$ 0.07 , and the interaction between the host of origin and the assayed host was significant with $P=10^{-7}$.

There was a positive correlation between the average accumulation of the isolates from each original host before (P0) and after $(\mathrm{P} 10 \mathrm{H})$ the passages (Spearman's coefficient $r_{s}=0.90[P=$ $0.0007]$, product-moment correlation coefficient $r=0.85$ ). Hence, variance of virus accumulation before and after 10 passages was determined by the isolates $\left(r^{2}=0.72\right)$. When correlation analyses were done separately for only accumulation in the host of origin, or for accumulation in heterologous hosts, similar results were obtained $\left(\chi_{1}^{2}=0.06, P=0.97\right.$, test of homogeneity among two or more correlation coefficients [46]).

The accumulation of CMV isolates from cucumber and tomato in their host of origin did not differ significantly before and after 10 passages $(P \geq 0.88)$. However, the accumulation of bean isolates in bean was significantly higher after 10 passages $(P=0.008)$. No significant differences were found in accumulation in heterologous hosts of any isolate before and after the passages $(P \geq$ 0.11 ), with the exception of isolates from cucumber assayed in tomato; $\mathrm{P} 10 \mathrm{H}$ preparations showed a significantly lower accumulation $\left(P=6 \times 10^{-4}\right)$ in this host than did the corresponding P0 preparations.

A similar series of 10 passages of the six CMV isolates in the host of origin was performed using a low inoculum dose (described previously). During this low inoculum dose passage process most lines became extinct before passage 10. At the end of the process, $\mathrm{P} 10 \mathrm{~L}$ preparations were obtained, and comparisons

TABLE 1. Frequency of plants infected with Cucumber mosaic virus isolates in different assayed hosts ${ }^{\mathrm{a}}$

\begin{tabular}{|c|c|c|c|c|c|c|}
\hline \multirow[b]{3}{*}{ Assay host } & \multicolumn{3}{|c|}{ P0 } & \multicolumn{3}{|c|}{$\mathrm{P} 10 \mathrm{H}$} \\
\hline & \multicolumn{3}{|c|}{ Original host } & \multicolumn{3}{|c|}{ Original host } \\
\hline & Cucumber & Bean & Tomato & Cucumber & Bean & Tomato \\
\hline Bean & (3/10) 0.30 & 0.90 & (5/10) 0.50 & (12/30) 0.40 & (25/30) 0.83 & 0.59 (17/29) \\
\hline Tomato & (10/10) 1.00 & 1.00 & 1.00 & (30/30) 1.00 & (30/30) 1.00 & (30/30) 1.00 \\
\hline
\end{tabular}

a Between parentheses, the number of infected plants over total inoculated for the original isolates $(\mathrm{P} 0)$ or after 10 passages at high inoculum dose $(\mathrm{P} 10 \mathrm{H})$ in the host of origin. Each of the P0 RNA preparations, or the RNA preparations from three P10H lines per isolate, was inoculated in five plants.

TABLE 2. Accumulation of Cucumber mosaic virus isolates in different assayed hosts ${ }^{\mathrm{a}}$

\begin{tabular}{|c|c|c|c|c|c|c|}
\hline \multirow[b]{3}{*}{ Assay host } & \multicolumn{3}{|c|}{$\mathrm{P} 0$} & \multicolumn{3}{|c|}{$\mathrm{P} 10 \mathrm{H}$} \\
\hline & \multicolumn{3}{|c|}{ Original host } & \multicolumn{3}{|c|}{ Original host } \\
\hline & Cucumber & Bean & Tomato & Cucumber & Bean & Tomato \\
\hline Cucumber & $15.2 \pm 6.3$ & $1.1 \pm 0.4$ & $10.7 \pm 6.31$ & $14.5 \pm 5.9$ & $0.5 \pm 0.1$ & $6.0 \pm 2.1$ \\
\hline Bean & $0.4 \pm 0.3$ & $0.4 \pm 0.1$ & $0.9 \pm 0.3$ & $0.4 \pm 0.2$ & $3.3 \pm 0.7$ & $2.7 \pm 0.6$ \\
\hline Tomato & $111.5 \pm 36.3$ & $11.8 \pm 4.6$ & $19.0 \pm 9.9$ & $50.1 \pm 25.6$ & $26.8 \pm 10.6$ & $31.9 \pm 14.0$ \\
\hline
\end{tabular}

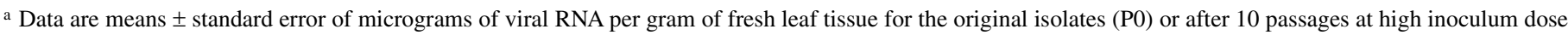
$(\mathrm{P} 10 \mathrm{H})$ in the host of origin. Each of the P0 RNA preparations, or the RNA preparations from three P10H lines per isolate, was inoculated in five plants. Only infected plants were considered. 
with $\mathrm{P} 10 \mathrm{H}$ preparations were possible only for one isolate per each host of origin: for three lines of isolates $\mathrm{Ph} / 94 / 13$ and T/99/4 and for two lines of isolate C/99/4. Table 3 shows virus accumulation in the original and heterologous hosts of these P10L preparations in comparison with the $\mathrm{P} 10 \mathrm{H}$ preparations of the same isolates. The accumulation of the P10L preparations of each isolate did not differ from that of the $\mathrm{P} 10 \mathrm{H}$ preparations in any host $(P \geq 0.08)$. Hence, 10 serial passages in the original host had no effect on virus accumulation for most isolate $\times$ host combinations, and no differences were found between the high and low inoculum dose experiments.

Relationship between CMV accumulation and the effect of CMV infection on host growth. The effect of CMV infection on host growth was estimated as the reduction in dry weight of stems and leaves of infected plants compared with that of mockinoculated controls (Tables 4 and 5). Except for infection of P0 preparations of tomato isolates in bean, CMV infection resulted in a significant reduction of growth in all cases.

Although CMV accumulation (Tables 2 and 3) was positively correlated with the effect of infection on host growth (Tables 4 and 5) (Spearman's coefficient $r_{s}=0.24\left[P<10^{-3}\right]$, productmoment correlation coefficient $r=0.12$ ), the relationship between the two variables only explained a low proportion of variance $\left(r^{2}=\right.$ 0.01 ). The relationship between accumulation and the effect of infection on host growth was the same before and after 10 passages for the original and heterologous hosts $\left(\chi^{2}{ }_{1}=0.21, P=0.65\right.$ and $\chi_{1}^{2}=0.56, P=0.46$, respectively, test of homogeneity among two or more correlation coefficients). Hence, virus accumulation was not a major determinant of the effect of infection on host growth.

The effect of infection on host growth by P0 preparations (Table 4) was significantly different for the three hosts $\left(P=10^{-4}\right)$, being lower for bean and higher for cucumber and tomato. The effect of infection on host growth also was significantly different according to the host of origin $(P=0.03)$, and the interaction between host of origin and assayed host also was significant $(P=$ 0.004). The effect of infection on growth of cucumber and tomato plants was less for bean isolates, as was the effect of infection on bean plant growth by tomato isolates $(P \leq 0.05$, least significant difference test of comparison of means).

The effect on growth of the host of origin for infection by P0 and $\mathrm{P} 10 \mathrm{H}$ preparations was correlated (Spearman's coefficient $r_{s}=0.77[P=0.04]$, product-moment correlation coefficient $r=$ 0.87 ) and the variance of the effect on host growth for infection with the CMV isolates before and after the passages was largely determined $\left(r^{2}=0.76\right)$ by the isolates. However, no correlation was found between the effect on the heterologous hosts for infection by $\mathrm{P} 0$ and $\mathrm{P} 10 \mathrm{H}$ preparations $(P=0.19)$. As for $\mathrm{P} 0$ preparations, the effect of infection by $\mathrm{P} 10 \mathrm{H}$ preparations was significantly different in each assayed host $\left(P=10^{-4}\right)$, with the effect being less in bean plants. Nonetheless, there were no significant differences according to the original host $(P=0.61)$. The interaction of original host and assayed host departed from random with $P=0.07$.

The effect of $\mathrm{P} 0$ and $\mathrm{P} 10 \mathrm{H}$ preparations on growth of the original host did not differ, except for cucumber isolates $(P>0.055)$, but differences were found for the heterologous hosts. Infection of cucumber plants by $\mathrm{P} 0$ and $\mathrm{P} 10 \mathrm{H}$ preparations of cucumber, bean, or tomato isolates had the same effect on growth $(P>0.17)$. Infection by $\mathrm{P} 10 \mathrm{H}$ preparations of cucumber isolates had a lower effect on growth of bean plants than infection by $\mathrm{P} 0$ preparations $(P=0.014)$, whereas infection by $\mathrm{P} 10 \mathrm{H}$ preparations of tomato isolates had a greater effect on bean plant growth than infection by $\mathrm{P} 0$ preparations $(P=0.034)$. Infection by $\mathrm{P} 10 \mathrm{H}$ preparations of

TABLE 3. Accumulation of Cucumber mosaic virus isolates after 10 passages at high and low inoculum dose in different assayed hosts ${ }^{\mathrm{a}}$

\begin{tabular}{|c|c|c|c|c|c|c|}
\hline \multirow[b]{2}{*}{ Assay host } & \multicolumn{3}{|c|}{$\mathrm{P} 10 \mathrm{H}$} & \multicolumn{3}{|c|}{ P10L } \\
\hline & C/99/4 & $\mathrm{Ph} / 94 / 13$ & $\mathrm{~T} / 99 / 4$ & C/99/4 & $\mathrm{Ph} / 94 / 13$ & $\mathrm{~T} / 99 / 4$ \\
\hline Cucumber & $31.9 \pm 11.5$ & $0.4 \pm 0.1$ & $8.7 \pm 3.4$ & $44.9 \pm 14.9$ & $0.7 \pm 0.4$ & $6.3 \pm 2.5$ \\
\hline Bean & $0.5 \pm 0.3$ & $3.3 \pm 1.1$ & $2.8 \pm 4.6$ & $0.0 \pm 0.2$ & $4.2 \pm 1.4$ & $2.9 \pm 0.6$ \\
\hline Tomato & $77.1 \pm 50.2$ & $48.4 \pm 20.5$ & $48.2 \pm 27.0$ & $25.0 \pm 6.4$ & $21.1 \pm 5.4$ & $13.6 \pm 4.5$ \\
\hline
\end{tabular}

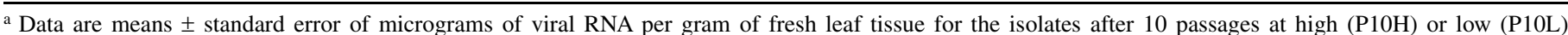
inoculum dose in the host of origin. Each preparations from two to three P10 lines per isolate, was inoculated in five plants. Only infected plants were considered.

TABLE 4. Effect of Cucumber mosaic virus infection on the growth of different assayed hosts ${ }^{\mathrm{a}}$

\begin{tabular}{|c|c|c|c|c|c|c|}
\hline \multirow[b]{3}{*}{ Assay host } & \multicolumn{3}{|c|}{$\mathrm{P} 0$} & \multicolumn{3}{|c|}{$\mathrm{P} 10 \mathrm{H}$} \\
\hline & \multicolumn{3}{|c|}{ Original host } & \multicolumn{3}{|c|}{ Original host } \\
\hline & Cucumber & Bean & Tomato & Cucumber & Bean & Tomato \\
\hline Cucumber & $0.63 \pm 0.08$ & $0.39 \pm 0.10$ & $0.60 \pm 0.08$ & $0.43 \pm 0.06$ & $0.48 \pm 0.05$ & $0.44 \pm 0.07$ \\
\hline Bean & $0.24 \pm 0.08$ & $0.21 \pm 0.04$ & $0.00 \pm 0.00$ & $0.07 \pm 0.03$ & $0.21 \pm 0.05$ & $0.19 \pm 0.04$ \\
\hline Tomato & $0.49 \pm 0.04$ & $0.32 \pm 0.07$ & $0.67 \pm 0.04$ & $0.68 \pm 0.04$ & $0.59 \pm 0.03$ & $0.69 \pm 0.04$ \\
\hline
\end{tabular}

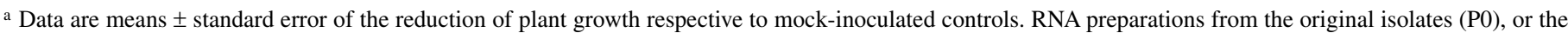
RNA preparations from three lines per isolate passaged 10 times in the original host $(\mathrm{P} 10 \mathrm{H})$, were inoculated into five plants. Only infected plants were considered.

TABLE 5. Effect of infection in different assayed hosts of Cucumber mosaic virus isolates after 10 passages at high and low inoculum dose in their original host ${ }^{\mathrm{a}}$

\begin{tabular}{|c|c|c|c|c|c|c|}
\hline \multirow[b]{2}{*}{ Assay host } & \multicolumn{3}{|c|}{$\mathrm{P} 10 \mathrm{H}$} & \multicolumn{3}{|c|}{ P10L } \\
\hline & $\mathrm{C} / 99 / 4$ & $\mathrm{Ph} / 94 / 13$ & $\mathrm{~T} / 99 / 4$ & $\mathrm{C} / 99 / 4$ & $\mathrm{Ph} / 94 / 13$ & $\mathrm{~T} / 99 / 4$ \\
\hline Cucumber & $0.37 \pm 0.09$ & $0.46 \pm 0.08$ & $0.29 \pm 0.11$ & $0.32 \pm 0.10$ & $0.38 \pm 0.09$ & $0.47 \pm 0.07$ \\
\hline Bean & $0.15 \pm 0.05$ & $0.26 \pm 0.08$ & $0.05 \pm 0.03$ & $0.21 \pm 0.07$ & $0.47 \pm 0.06$ & $0.36 \pm 0.10$ \\
\hline Tomato & $0.78 \pm 0.03$ & $0.57 \pm 0.05$ & $0.67 \pm 0.03$ & $0.70 \pm 0.05$ & $0.43 \pm 0.08$ & $0.70 \pm 0.04$ \\
\hline
\end{tabular}

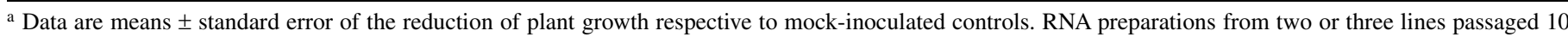
times in the host of origin per isolate at high $(\mathrm{P} 10 \mathrm{H})$ or low $(\mathrm{P} 10 \mathrm{~L})$ inoculum dose were inoculated into five plants. Only infected plants were considered. 
cucumber and bean isolates had a greater effect on growth of tomato plants than did infection by $\mathrm{P} 0$ preparations of these isolates $(P \leq 0.01)$. Hence, the effect of high dose passages on the capacity of the CMV isolates for accumulation in different hosts, and on their capacity to affect host growth, was different (compare Tables 2 and 4, summarized in Table 6).

Inoculum dose did not affect the capacity of CMV isolates to diminish host plant growth $(P \geq 0.09)$ (Table 6). Only for isolates $\mathrm{T} / 99 / 4$ and $\mathrm{Ph} / 94 / 13$ assayed in bean was a significant difference found, with $\mathrm{P} 10 \mathrm{~L}$ preparations having a greater effect than $\mathrm{P} 10 \mathrm{H}$ preparations $(P=0.05)$.

Changes in the genome of CMV after the serial passages in the original host at different inoculum doses. To ascertain if 10 passages had any genetic effect on the CMV isolates, a molecular characterization of the $\mathrm{P} 0, \mathrm{P} 10 \mathrm{H}$, and $\mathrm{P} 10 \mathrm{~L}$ preparations was done. The consensus sequences of three randomly chosen fragments of the genomic RNAs were analyzed: a 734-nucleotide-long fragment from RNA 1, a 594-nucleotide-long fragment from RNA 2, and a 416-nucleotide-long fragment from RNA 3. To analyze possible genetic changes resulting from the passages, the sequences of the P10 preparations of each isolate were compared with that of the P0 preparation. Also, genetic divergence among the sequences of the $\mathrm{P} 10 \mathrm{H}$ and $\mathrm{P} 10 \mathrm{~L}$ lines of each isolate was estimated. Table 7 presents the mean p-distances between each P0 and $\mathrm{P} 10$ preparation for each isolate, and Table 8 presents mean p-distances among the P10 preparations for the $\mathrm{H}$ and $\mathrm{L}$ lines of each isolate. Table 7 shows that high inoculum dose passages resulted in a significant diversification of at least one of the genomic segments for five of the isolates (mean p-distance significantly different from zero, indicated by asterisks in Table 7), the exception being isolate T/99/4. Low inoculum dose passages resulted in significant diversification of at least one genomic segment for the three analyzed isolates. Table 8 shows that for all isolates that had diversified from P0 during the passages, diversification was different among the analyzed lines, at least for one genomic segment, as shown by mean among-line p-distances significantly different from zero (asterisks in Table 8). Significant p-distances between each original isolate and the lines obtained after passaging and significant among-line diversification were correlated (Spearman's coefficient $r_{s}=0.89,[P<0.001]$, productmoment correlation coefficient $r=0.91)$ and were independent of inoculum dose $\left(\chi_{1}^{2} \leq 1.4, P \geq 0.36\right)$, the host of origin $\left(\chi_{2}^{2} \leq 0.31\right.$, $P=1)$, or the analyzed genomic RNA segment $\left(\chi_{2}^{2} \leq 2.1, P \geq\right.$ 0.40). However, the p-distances between each original P0 sequence and those of the corresponding $\mathrm{P} 10 \mathrm{H}$ and $\mathrm{P} 10 \mathrm{~L}$ lines were correlated between RNA 1 and RNA $3\left(r_{s}=0.67, P=\right.$ $0.049)$, but not between RNA 2 and RNA $1(P=0.32)$ or RNA 3 $(P=0.54)$. This indicates that the evolution during the passages of RNAs 1 and 3, but not of RNA 2, was related.

\section{DISCUSSION}

The processes that result in adaptation of a pathogen to a new host have been studied by analysis of genotypic and phenotypic

TABLE 6. Effect of 10 passages at high inoculum dose in the host of origin on the accumulation (A) and on the effect of infection on host growth (V) for Cucumber mosaic virus isolates ${ }^{\mathrm{a}}$

\begin{tabular}{|c|c|c|c|c|c|c|}
\hline \multirow[b]{3}{*}{ Assay host } & \multicolumn{6}{|c|}{ Original host } \\
\hline & \multicolumn{2}{|c|}{ Cucumber } & \multicolumn{2}{|c|}{ Bean } & \multicolumn{2}{|c|}{ Tomato } \\
\hline & A & V & A & $\mathrm{V}$ & A & V \\
\hline Cucumber & $\leftrightarrow$ & $\downarrow$ & $\leftrightarrow$ & $\leftrightarrow$ & $\leftrightarrow$ & $\leftrightarrow$ \\
\hline Bean & $\leftrightarrow$ & $\downarrow$ & $\uparrow$ & $\leftrightarrow$ & $\leftrightarrow$ & $\uparrow$ \\
\hline Tomato & $\downarrow$ & $\uparrow$ & $\leftrightarrow$ & $\uparrow$ & $\leftrightarrow$ & $\leftrightarrow$ \\
\hline
\end{tabular}

a Symbols indicate comparisons of passaged lines (P10H preparations) with the original isolate (P0 preparation): $\leftrightarrow$, no change; $\uparrow$, increase; $\downarrow$, decrease. changes of a population subjected to serial passages in a heterologous host $(7,9,48)$. In these studies, the term adaptation implies a comparison of fitness before and after experimental evolution. Data on host adaptation of natural populations of pathogens, on the influence that trade-offs between the different hosts may have on host adaptation, and on the relationship between host adaptation and virulence are rare. One approach to the study of host adaptation in natural populations is to compare the ability of different isolates to multiply in their host of origin and in heterologous hosts. The existence of host adaptation is deduced from the observation of a host-dependent differential fitness (6). Two assumptions underlie this approach. (i) There is a trade-off in the adaptation to different hosts. (ii) The fitness of the assayed strains has reached its optimum level in relation to the conditions (i.e., the host) in which they were isolated. The verification of these two assumptions is important to understand the evolution of generalist pathogens, particularly when this strategy is supposed to be driven by seasonal alternation among hosts, as it may be the case for pathogens of annual crops.

In this work, we have analyzed the host adaptation status of CMV populations by comparing fitness of six CMV isolates in their host of origin and in other hosts before and after serial passage in their host of origin, rather than in a new host as is usually done. This process would tend to suppress the unknown historical contingencies undergone by each isolate before being collected, which would ensure that the differences revealed among isolates

TABLE 7. Nucleotide diversity between original Cucumber mosaic virus isolates and the different lines resulting from 10 passages in the host of origin ${ }^{\text {a }}$

\begin{tabular}{llll}
\hline Isolate $^{\text {b }}$ & \multicolumn{1}{c}{ RNA 1 } & \multicolumn{1}{c}{ RNA 2 } & \multicolumn{1}{c}{ RNA 3 } \\
\hline C/99/4 H & $0.0009 \pm 0.0006$ & $0.0079 \pm 0.0034^{*}$ & $0.0081 \pm 0.0024^{*}$ \\
$\mathrm{C} / 99 / 4 \mathrm{~L}$ & $0.0020 \pm 0.0011$ & $0.0168 \pm 0.0047^{*}$ & $0.0000 \pm 0.0000$ \\
$\mathrm{C} / 99 / 5 \mathrm{H}$ & $0.0073 \pm 0.0021^{*}$ & $0.0017 \pm 0.0010$ & $0.0056 \pm 0.0023^{*}$ \\
$\mathrm{Ph} / 94 / 12 \mathrm{H}$ & $0.0009 \pm 0.0006$ & $0.0348 \pm 0.0056^{*}$ & $0.0032 \pm 0.0019$ \\
$\mathrm{Ph} / 94 / 13 \mathrm{H}$ & $0.0149 \pm 0.0039^{*}$ & $0.0006 \pm 0.0005$ & $0.0177 \pm 0.0042^{*}$ \\
$\mathrm{Ph} / 94 / 13 \mathrm{~L}$ & $0.0014 \pm 0.0013$ & $0.0101 \pm 0.0024^{*}$ & $0.0000 \pm 0.0000$ \\
$\mathrm{~T} / 93 / 2 \mathrm{H}$ & $0.0077 \pm 0.0019^{*}$ & $0.0067 \pm 0.0030^{*}$ & $0.0306 \pm 0.0048^{*}$ \\
$\mathrm{~T} / 99 / 4 \mathrm{H}$ & $0.0009 \pm 0.0006$ & $0.0006 \pm 0.0005$ & $0.0000 \pm 0.0000$ \\
$\mathrm{~T} / 99 / 4 \mathrm{~L}$ & $0.0009 \pm 0.0006$ & $0.0000 \pm 0.0000$ & $0.0048 \pm 0.0019^{*}$
\end{tabular}

a Data are means \pm standard error of p-distances for the consensus sequence of a 734-nt-long fragment for RNA 1, a 594-nt-long fragment for RNA 2, and a 416-nt-long fragment for RNA 3, for two or three lines passaged 10 times in the host of origin at high or low inoculum dose. Asterisks indicate means significantly different from zero.

b The isolate's name followed by the letters $\mathrm{H}$ (for high inoculum dose passages) or L (for low inoculum dose passages) indicates the group of sequences compared with the original $\mathrm{P} 0$.

TABLE 8. Nucleotide diversity among different lines of Cucumber mosaic virus isolates passaged 10 times in the host of origin ${ }^{\mathrm{a}}$

\begin{tabular}{llll}
\hline Isolate $^{\mathrm{b}}$ & \multicolumn{1}{c}{ RNA 1 } & \multicolumn{1}{c}{ RNA 2 } & \multicolumn{1}{c}{ RNA 3 } \\
\hline $\mathrm{C} / 99 / 4 \mathrm{H}$ & $0.0018 \pm 0.0012$ & $0.0022 \pm 0.0015$ & $0.0161 \pm 0.0047^{*}$ \\
$\mathrm{C} / 99 / 4 \mathrm{~L}$ & $0.0041 \pm 0.0022^{*}$ & $0.0101 \pm 0.0039^{*}$ & $0.0000 \pm 0.0000$ \\
$\mathrm{C} / 99 / 5 \mathrm{H}$ & $0.0118 \pm 0.0030^{*}$ & $0.0034 \pm 0.0019$ & $0.0105 \pm 0.0041^{*}$ \\
$\mathrm{Ph} / 94 / 12 \mathrm{H}$ & $0.0018 \pm 0.0013$ & $0.0393 \pm 0.0063^{*}$ & $0.0048 \pm 0.0027$ \\
$\mathrm{Ph} / 94 / 13 \mathrm{H}$ & $0.0260 \pm 0.0068^{*}$ & $0.0011 \pm 0.0011$ & $0.0322 \pm 0.0073^{*}$ \\
$\mathrm{Ph} / 94 / 13 \mathrm{~L}$ & $0.0000 \pm 0.0000$ & $0.0196 \pm 0.0046^{*}$ & $0.0000 \pm 0.0000$ \\
$\mathrm{~T} / 93 / 2 \mathrm{H}$ & $0.0146 \pm 0.0035^{*}$ & $0.0022 \pm 0.0015$ & $0.0596 \pm 0.0092^{*}$ \\
$\mathrm{~T} / 99 / 4 \mathrm{H}$ & $0.0018 \pm 0.0012$ & $0.0011 \pm 0.0011$ & $0.0000 \pm 0.0000$ \\
$\mathrm{~T} / 99 / 4 \mathrm{~L}$ & $0.0018 \pm 0.0012$ & $0.0000 \pm 0.0000$ & $0.0097 \pm 0.0038^{*}$ \\
\hline
\end{tabular}

a Data are means \pm standard error of p-distances for the consensus sequence of a 734-nt-long fragment for RNA 1, a 594-nt-long fragment for RNA 2, and a 416-nt-long fragment for RNA 3, for two or three lines passaged 10 times in the host of origin at high or low inoculum dose. Asterisks indicate means significantly different from zero.

b The isolate's name followed by the letter $\mathrm{H}$ (for high inoculum dose passages) or L (for low inoculum dose passages) indicates the group of sequences considered. 
from different hosts, if any, would be due to host plants and not to other factors in the isolate's history. The experiment was designed to illustrate the following issues: (i) whether CMV isolates were adapted or not to their host of origin; (ii) whether host adaptation could be improved by serial passages, or the assayed CMV isolates had reached their optimum fitness in the host of origin; (iii) if there were trade-offs in the adaptation to different hosts that prevent achievement of maximum fitness; and (iv) if there is a relationship between fitness and virulence for this system. Fitness was estimated as the ability of the virus to multiply in the plant, measured as virus accumulation and infectivity. Virulence was estimated as the effect of virus infection on host growth (11).

No difference was detected in accumulation of the CMV isolates before the passages ( $\mathrm{P} 0$ preparations) according to their host (Table 2), suggesting that there was no host-dependent differential fitness. However, a host-dependent differential infectivity in bean, the least permissive host, was apparent, as bean isolates were more infectious to bean than were isolates from cucumber or tomato (Table 1). Infectivity is a component of fitness related to between-host transmission, and these results support the hypothesis of a differential fitness according to the host of origin. It needs to be pointed that CMV is horizontally transmitted by aphids, and infectivity by mechanical and by aphid transmission could differ. However, the results in Table 1 necessarily indicate the intrinsic infectivity of each isolate in each host, as every assayed RNA preparation was $100 \%$ infectious in some host. This shows that mechanical inoculation ensured entrance of infectious inocula in the host cells and, hence, our infectivity results are not dependent on other phenomena as would be, for instance, differential behavior of aphids in different host's plant species. The ability of the bean isolates to multiply in bean was higher after 10 passages in this host species (Table 2), indicating that this component of fitness was open to improvement. These results suggest that there are trade-offs that impeded fitness gain. Because accumulation of bean isolates in the heterologous hosts did not change after passage, original fitness levels cannot be attributed to trade-offs in the adaptation to different hosts. We could speculate on the role of other trade-offs in the life history of the virus, for instance between within host multiplication and transmission $(19,38)$. The accumulation of cucumber isolates in tomato was lower after 10 passages in cucumber, suggesting that there is a trade-off in the adaptation of CMV to cucumber versus tomato. Since accumulation of cucumber isolates in cucumber was not higher after 10 passages, this trade-off would not be of an antagonistic pleiotropic nature (14), but could be due to mutations neutral for accumulation in cucumber and deleterious for accumulation in tomato (9).

Passage experiments with animal-infecting bacteria and viruses, involving a change of environment (reviewed in 9), have shown that fitness gains are initially rapid but tend to decelerate in later passages, indicating that in a new environment populations are evolving from a region of lower fitness toward an adaptive peak (9). Similarly, experiments have shown that adaptation of CMV to new hosts occurs quickly and may be detected after three passages (48). Hence, no detectable changes in accumulation after 10 passages in the original host indicate that fitness of the CMV isolates was at, or near to, maximum for the host of origin. In this respect it is interesting that an improvement of fitness after 10 passages was detected only in the most restrictive host, bean. Since accumulation of the CMV isolates did not increase with passage, and was not related to the original hosts, our results indicate that host-dependent multiplication is not a factor determining population structure. However, host-associated differences in infectivity were detected in the original isolates and did not change with passage, suggesting that infectivity may be a conditional trait in the virus life cycle. Infectivity is an important component of fitness for parasites, and host-associated differences in infectivity could result in population differentiation according to hosts. Detailed analysis of the dynamics and genetic structure of CMV populations in different habitats and hosts in central Spain provided no evidence of a host-associated population structure $(2,41)$, suggesting that differential infectivity, as estimated in this work, is not so efficient to promote population differentiation. Alternatively, aphid transmission may affect infectivity. These two hypotheses should be further analyzed.

Schneider and Roossinck (44) have analyzed genotypic changes of a CMV population during 10 passages, finding no variation in the consensus sequence during the process. Experiments with Wheat streak mosaic virus (WSMV) found no evidence of hostdriven evolution in wheat, the original host, where the singleton frequency per nucleotide remained constant after passage (18). These results are compatible with the limited changes to be expected for populations near the adaptive peak (9). The low diversification in the consensus sequences of the lines of the passaged isolates detected in this work (Tables 7 and 8) agrees with these results and can be similarly interpreted. An interesting result was that RNAs 1 and 3, but not RNA 2, have followed similar evolutionary dynamics. Because RNAs 1 and 2 encode proteins that must interact for viral RNA replication, this result indicates that the evolutionary dynamics of different CMV genes may be independent, regardless of linked function, and agree with results from phylogenetic analyses of CMV (35). Genetic diversification was similar for lines passaged at high and at low inoculum doses, a result we did not expect on the basis of literature reports $(30,33)$. However, we must point out that many of the high inoculum passage lines, and most of the low inoculum passage ones, were lost during passages. Particularly for inoculations at low inoculum doses this could have resulted from applying the inoculum below the dilution end point. However, infectivity of inocula was always checked by local lesion assay in $C$. quinoa at two different dilutions, and successful infections were always obtained from lyophilized material from the passage previous to extinction, which suggests that we have rescued only the genotypes that were not overcome by genetic meltdown in a Muller's ratchet process (27). Analysis of bottlenecks in the populations of Tobacco mosaic virus and WSMV during the colonization of their host plants indicate small effective population sizes $(13,42)$, compatible with strong genetic drift leading to genetic meltdown. A recent report indicates that this also may be the case for CMV (24).

A major goal of our work was to analyze the relationship between virus multiplication and virulence. Most theoretical analyses of virulence evolution assume that there is a positive relation between multiplication rate and effect of the pathogen on the host (i.e., virulence), although there are limited data and controversy on this issue $(4,8)$. At odds with our results on virus accumulation, the effect of the unpassaged isolates in the three hosts depended on the original host of the isolate, and there was an interaction between host of origin of the isolates and assayed host (Table 4). This indicates that there is a relationship between virulence and host independent of virus multiplication. In agreement to this, our results showed no correlation between accumulation of CMV isolates and effect on host growth. Moreover, the serial passages resulted in a modification of virulence in the three hosts even when virus accumulation did not change (Table 6), also indicating that virus multiplication and virulence were uncoupled. These results do not, therefore, support the hypothesis that virulence is an unavoidable consequence of the multiplication of the pathogens (8). Moreover, since our results indicated that virus accumulation was maximal for the host of origin, the level of virulence cannot be considered a consequence of maladaptation of the pathogen $(5,23)$. Hence, the results presented in this paper are a warning against the general application to any host-pathogen system of the trade-off models of virulence evolution. 


\section{ACKNOWLEDGMENTS}

We thank A. L. Quirós and B. Prieto for excellent technical assistance. This work was supported in part by grant AGL2002-00743 from Ministerio de Ciencia y Tecnología, Spain, to F. García-Arenal. S. Sacristán was supported by a fellowship of the programme Formación de Profesorado Universitario, Ministerio de Educación y Cultura, Spain.

\section{LITERATURE CITED}

1. Anderson, R. M., and May, R. M. 1982. Coevolution of hosts and parasites. Parasitology 85:411-426.

2. Bonnet, J., Fraile, A., Sacristan, S., Malpica, J. M., and García-Arenal, F. 2005. Role of recombination in the evolution of natural populations of Cucumber mosaic virus, a tripartite RNA plant virus. Virology 332:359368.

3. Boonham, N., and Word, R. K. 1998. Assaying levels of virus with local lesion hosts. Pages 487-496 in: Plant Virology Protocols. From Virus Isolation to Transgenic Resistance. Humana Press, Totowa, NJ.

4. Bull, J. J. 1994. Perspective virulence. Evol. Int. J. Org. Evol. 48:1423-1437.

5. Combes, C. 1997. Fitness of parasites: Pathology and selection. Int. J. Parasitol. 27:1-10.

6. Dybdahl, M. F., and Storfer, A. 2003. Parasite local adaptation: Red Queen versus Suicide King. Trends Ecol. Evol. 18:523-530.

7. Ebert, D. 1998. Experimental evolution of parasites. Science 282:14321435.

8. Ebert, D., and Bull, J. J. 2003. Challenging the trade-off model for the evolution of virulence: Is virulence management feasible? Trends Microbiol. 11:15-20.

9. Elena, S. F., and Lenski, R. E. 2003. Evolution experiments with microorganisms: The dynamics and genetics bases of adaptation. Nat. Rev. Gen. 4:457-469.

10. Escriu, F., Fraile, A., and García-Arenal, F. 2000. Evolution of virulence in natural populations of the satellite RNA of Cucumber mosaic virus. Phytopathology 90:480-485.

11. Escriu, F., Fraile, A., and Garcia-Arenal, F. 2003. The evolution of virulence in a plant virus. Evol. Int. J. Org. Evol. 57:755-765.

12. Frank, S. A. 1996. Models of parasite virulence. Q. Rev. Biol. 71:37-78.

13. French, R., and Stenger, D. C. 2003. Evolution of wheat streak mosaic virus: Dynamics of population growth within plants may explain limited variation. Annu. Rev. Phytopathol. 41:199-214.

14. Fry, J. D. 1990. Trade-offs in fitness on different hosts: Evidence from a selection experiment with a phytophagous mite. Am. Nat. 136:569-580.

15. García-Arenal, F., and McDonald, B. A. 2003. An analysis of the durability of resistance to plant viruses. Phytopathology 93:941-952.

16. Gerlach, W. L., and Bedbrook, J. R. 1979. Cloning and characterization of ribosomal RNA genes from wheat and barley. Nucleic Acids Res. 7:18691885.

17. Gonsalves, D., Providenti, R., and Edwards, M. C. 1982. Tomato white leaf: The relation of an apparent satellite RNA and cucumber mosaic virus. Phytopathology 72:1533-1538.

18. Hall, J. S., French, R., Morris, T. J., and Stenger, D. C. 2001. Structure and temporal dynamics of populations within Wheat streak mosaic virus isolates. J. Virol. 75:10231-10243.

19. Harrison, B. D. 1981. Plant virus ecology: Ingredients, interactions and environmental influences. Ann. Appl. Biol. 99:195-209.

20. Harrison, B. D. 2002. Virus variation in relation to resistance breaking plants. Euphytica 124:181-192.

21. Kofalvi, S., Marcos, J., Canizares, M., Pallas, V., and Candresse, T. 1997. Hop stunt viroid (HSVd) sequence variants from Prunus species: Evidence for recombination between HSVd isolates. J. Gen. Virol. 78:31773186.

22. Kruskal, W. H., and Wallis, W. A. 1952. Use of ranks in one-criterion variance analysis. J. Am. Stat. Assn. 47:583-621.
23. Lajeunesse, M. J., and Forbes, M. R. 2002. Host range and local parasite adaptation. Proc. R. Soc. Lond. B Biol. Sci. 269:703-710.

24. Li, H., and Roossinck, M. J. 2004. Genetic bottlenecks reduce population variation in an experimental RNA virus population. J. Virol. 78:1058210587.

25. Lively, C. M., and Dybdahl, M. F. 2000. Parasite adaptation to locally common host genotypes. Nature 405:679-681.

26. Lot, H., Marrou, J., Quiot, J. B., and Esvan, C. 1972. Contribution à l'ètude du virus de la mosaïque du concombre (CMV). Méthode de purification rapide du virus. Ann. Phytopathol. 4:25-38.

27. Lynch, M., Burger, R., Butcher, D., and Gabriel, W. 1993. The mutational meltdown in asexual populations. J. Hered. 84:339-344.

28. Mastari, J., Lapierre, H., and Dessens, J. T. 1998. Asymmetrical distribution of barley yellow dwarf virus PAV variants between host plant species. Phytopathology 88:818-821.

29. May, R. M., and Nowak, M. A. 1995. Coinfection and the evolution of parasite virulence. Proc. R. Soc. Lond. B Biol. Sci. 261:209-215.

30. Miralles, R., Moya, A., and Elena, S. F. 2000. Diminishing returns of population size in the rate of RNA virus adaptation. J. Virol. 74:35663571.

31. Moury, B., Cardin, L., Onesto, J.-P., Candresse, T., and Poupet, A. 2001. Survey of Prunus necrotic ringspot virus in rose and its variability in rose and in Prunus spp. Phytopathology 91:84-91.

32. Nei, M. 1987. Molecular Evolutionary Genetics. Columbia University Press, New York.

33. Novella, I. S., Elena, S. F., Moya, A., Domingo, E., and Holland, J. J. 1995. Size of genetic bottlenecks leading to virus fitness loss is determined by mean initial population fitness. J. Virol. 69:2869-2872.

34. Palukaitis, P., and García-Arenal, F. 2003. Cucumber mosaic virus. No. 400 in: Description of Plant Viruses. Assoc. Appl. Biol., Kew, England.

35. Palukaitis, P., and García-Arenal, F. 2003. Cucumoviruses. Adv. Virus Res. 62:242-300.

36. Palukaitis, P., Roossinck, M. J., Dietzgen, R. G., and Francki, R. I. B. 1992. Cucumber mosaic virus. Adv. Virus Res. 41:281-348.

37. Pfenning, K. S. 2001. Evolution of pathogen virulence: The role of variation in host phenotype. Proc. R. Soc. Lond. B Biol. Sci. 268:755-760.

38. Power, A. G. 1992. Patterns of virulence and benevolence in insect-borne pathogens of plants. Crit. Rev. Plant Sci. 11:351-372.

39. Read, A. F. 1994. The evolution of virulence. Trends Microbiol. 2:73-76.

40. Regoes, R. R., Nowak, M. A., and Bonhoeffer, S. 2000. Evolution of virulence in a heterogeneous host population. Evol. Int. J. Org. Evol. 54:64-71.

41. Sacristan, S., Fraile, A., and García-Arenal, F. 2004. Population dynamics of Cucumber mosaic virus in melon crops and in weeds in Central Spain. Phytopathology 94:992-998.

42. Sacristan, S., Malpica, J. M., Fraile, A., and Garcia-Arenal, F. 2003. Estimation of population bottlenecks during systemic movement of tobacco mosaic virus in tobacco plants. J. Virol. 77:9906-9911.

43. Scheirer, C. J., Ray, W. S., and Hare, N. 1976. The analysis of ranked data derived from completely randomized factorial designs. Biometrics $32: 429-434$.

44. Schneider, W. L., and Roossinck, M. J. 2000. Evolutionarily related Sindbis-like plant viruses maintain different levels of population diversity in a common host. J. Virol. 74:3130-3134.

45. Skotnicki, M. L., Mackenzie, A. M., and Gibbs, A. J. 1996. Genetic variation in populations of Kennedya yellow mosaic tymovirus. Arch. Virol. 141:99-110.

46. Sokal, R. R., and Rohlf, F. J. 1995. Biometry. 3rd ed. W. H. Freeman and Company, New York.

47. Thompson, J. D., Higgins, D. G., and Gibson, T. J. 1994. CLUSTAL W: Improving the sensitivity of progressive multiple sequence alignment through sequence weighting, position specific gap penalties and weight matrix choice. Nucleic Acids Res. 22:4673-4680.

48. Yarwood, C. E. 1979. Host passage effects with plant viruses. Adv. Virus Res. 24:169-191. 